Tserkovniuk R., Yanchij R., Plyska O., Kovbasnyuk M., Chendey I., Popovych I., Hagner-Derengowska M., Zukow X., Kałużny K., Muszkieta R., Zukow W. Relationships between geomagnetic Ap-index and parameters of the immunity in patients with neuroendocrineimmune complex dysfunction in former sportsmen. Journal of Education, Health and Sport. 2021;11(7):335-348. eISSN 2391-8306. DOI http://dx.doi.org/10.12775/JEHS.2021.11.07.034 https://apcz.umk.pl/czasopisma/index.php/JEHS/article/view/JEHS.2021.11.07.034 https://zenodo.org/record/5855875

\footnotetext{
The journal has had 5 points in Ministry of Science and Higher Education parametric evaluation. § 8. 2) and § 12. 1. 2) 22.02.2019. (c) The Authors 2021

This article is published with open access at Licensee Open Journal Systems of Nicolaus Copernicus University in Torun, PolandOpen Access. This article is distributed under the terms of the Creative Commons Attribution Noncommercial License which permits any noncommercial use, distribution, and reproduction in any medium,provided the original author (s) and source are credited. This is an open access article licensed under the terms of the Creative Commons Attribution Non commercial license Share

alike.(http://creativecommons.org/licenses/by-nc-sa/4.0/) which permits unrestricted, non commercial use, distribution and reproduction in any medium, provided the work is properly cited.The authors declare that there is no conflict of interests regarding the publication of this paper.
}

Received: 10.07.2021. Revised: 20.07.2021. Accepted: 30.07.2021

\title{
Relationships between geomagnetic Ap-index and parameters of the immunity in patients with neuroendocrine-immune complex dysfunction in former sportsmen
}

\author{
Ruslan Tserkovniuk ${ }^{1}$, Roman Yanchij ${ }^{2}$, Oleksandr Plyska ${ }^{3}$, Marta Kovbasnyuk ${ }^{2}$, \\ Ivanna Chendey ${ }^{4}$, Igor Popovych ${ }^{1,2}$, Magdalena Hagner-Derengowska ${ }^{5}$, Xawery Zukow ${ }^{6}$, \\ Krystian Kałużny ${ }^{7}$, Radosław Muszkieta ${ }^{5}$, Walery Zukow ${ }^{5 *}$ \\ ${ }^{1}$ Ukrainian Research Institute for Medicine of Transport, Odesa, Ukraine \\ ${ }^{2} \mathrm{OO}$ Bohomolets' Institute of Physiology, Kyïv, Ukraine \\ ${ }^{3}$ National Pedagogical Dragomanov University, Kyïv, Ukraine \\ ${ }^{4}$ Danylo Galyts'kyǐ National Medical University, L'viv, Ukraine \\ ${ }^{5}$ Nicolaus Copernicus University, Toruń, Poland \\ ${ }^{6}$ Medical University of Bialystok, Bialystok, Poland \\ ${ }^{7}$ Faculty of Health Sciences, Ludwik Rydygier Collegium Medicum in Bydgoszcz, Nicolaus \\ Copernicus University, Toruń, Poland \\ *w.zukow@wp.pl
}

\begin{abstract}
Background. The effect of geomagnetism on human immunity has so far been studied through long-term observations. Recently, we have been detected the immediate immunotropic effects of the disturbances of the geomagnetic field (Ap-index) at multiple sclerosis patients. The aim of this study was to identify the immunotropic effects of geomagnetism on another contingent of people. Material and methods. The object of observation were 21 men (24-63 y) and 20 women (33-62 y) with neuroendocrine-immune complex dysfunction. Each patient was tested twice with an interval of 4 days. Observations were carried out on 09.06. and 13.06. 2015, 14.09 and 18.09. 2015, 27-28.03. and 04-05.04. 2018, 28.01. and 01.02. 2019. Retrospectively we recorded the geomagnetic Ap-Index on the day of testing and during the previous 7 days, using resource https://www.spaceweatherlive.com/. The content of subpopulations of lymphocytes expressing CD3, CD4, CD25, CD8, CD22 and CD56 receptors as well as the serum concentration of circulating immune complexes, immunoglobulins classes $\mathrm{M}, \mathrm{G}, \mathrm{A}, \mathrm{C}$-reactive protein and IL-1 $\beta$
\end{abstract}


was determined. The state of phagocytic function of neutrophils estimated by microbial count and phagocytic and killing indices against Staphylococcus aureus and Escherichia coli. Results. During the week, the average level of Ap-index ranged from 7 to $13 \mathrm{nT}$. Maximum coefficients of multiple correlation with immunity parameters were detected for Ap-index on the eve of blood sampling $(R=0,768)$ and 5 days before it $(R=0,758)$ while the minimum on $3(R=0,541)$ and 2 $(\mathrm{R}=0,479)$ days before sampling. The canonical correlation between Ap-indices for 7 days before and on the day of testing, on the one hand, and the immunity parameters - on the other hand, was very strong: $\mathrm{R}=0,921 ; \mathrm{R}^{2}=0,849 ; \chi_{(200)}^{2}=375 ; \mathrm{p}<10^{-6}$. Conclusion. Disturbances of the geomagnetic field (Ap-index) has a significant immediate modulating effect on the immune parameters, mostly phagocytosis completeness, Igg A and M serum concentration, T-helper and B lymphocytes as well as eosinophils, rod-shaped neutrophils and monocytes blood level.

Key words: geomagnetic Ap-index, immunity, relationships, humans.

\section{Introduction}

Back in 1936 the founder of Heliobiology AL Chizhevsky [1,2] suggested correlation of some biological processes on the Earth with cycles of Solar activity. But possible mechanisms of such interrelation are still not completely understood.

The geomagnetic field is a fundamental nature of the planet that is produced by the geodynamo of the Earth's outer core. There is evidence that changes in this field can affect biological systems $[3,4]$. The presence of this field is vital for saving the atmosphere and the life on our planet from the dangerous particles of solar winds and cosmic radiations. While geomagnetic field deflects the solar wind particles, any changes in the density or the velocity of the solar wind interact with the magnetosphere and cause temporary alterations in the field that is measurable at the Earth surface [5]. This phenomenon is called geomagnetic disturbance or geomagnetic activity. The concept of space-weather is relatively new and the main researches about this phenomenon have been done in recent four decades [6]. Moreover, as geomagnetic field and its disturbances are categorized as very low magnetic field without thermal and ionizing effect, their effects on physiological and pathophysiological issues, in comparison to other environmental factors, have generally been neglected by most biologists [4]. Space around our planet is not empty and the Earth is immersed in the solar energetic charged particles. Spaceweather defined as the conditions in space that affect Earth, consequences of flowing ionized particle of the solar wind against geomagnetic field. However, geomagnetic field acts like a shield and deflect most of the solar charged particles, it is also impressed and altered by solar wind [6]. These geomagnetic field alterations are called geomagnetic disturbances. For quantifying geomagnetic disturbances, several indices such as Planetary $\mathrm{K}$ index (Kp) and Planetary A index (Ap) were defined. 
F Abdollahi and SA Sajedi [7] studied the association between alterations in the solar wind velocity $\left(\mathrm{V}_{\mathrm{Sw}}\right)$ and planetary $\mathrm{A}$ index $\left(A_{P}\right.$, geomagnetic disturbances index) with multiple sclerosis (MS) incidence in Tehran and western Greece, during the $23^{\text {rd }}$ solar cycle (1996-2008), by an ecologicalcorrelational study. They found moderate to strong correlations among MS incidence of Tehran with $\mathrm{V}_{\mathrm{Sw}}\left(\mathrm{r}_{\mathrm{S}}=0,665\right)$, with 1 y delay, and also with $A_{P}\left(r_{S}=0,864\right)$ with 2 y delay. There were very strong correlations among MS incidence data of Greece with $V_{S w}$ $(r=0,906)$ and with $A_{P}(r=0,844)$, both with 1 $\mathrm{y}$ lag. In addition, significant positive correlations between geomagnetic disturbances and MS incidence were seen in Tayside County (at lag of 2 ys: $r_{S}=0,38$ ), Denmark (peak correlation at lag of 2 ys: $r_{S}=0,53$ ), and UK (at lag of $1 \mathrm{y}: r_{S}=0,50$ ) [8].

It was shown that human brain contains magnetites [9] and it was proposed that observed increases in stress hormones, heart rate, and the amount of myocardial infarctions during geomagnetic storms may induced by causing an adaptive stress reaction through the effect of geomagnetic disturbances on brain magnetosomes $[10,11]$. Accordingly, histochemical finding about the presence of considerable iron deposits within myelin loops [12] and evidences from imaging technics about increased iron deposits in subcortical gray matters of MS patients [13], in addition to some results about greater incidence of cardiovascular diseases among MS patients [14], all may be regarded as indirect clues of a probable relation among the effects of geomagnetic disturbances on brain magnetosomes and pathogenesis of MS.

However, there is also an immunological aspect to the relationship between geomagnetic disturbances and pathogenesis of MS. Given that in MS the immune system damages the CNS, MS is considered to be an autoimmune disease. The etiology of MS is not well understood, but it is believed that myelin-specific $\mathrm{CD}^{+}$ $\mathrm{T}$ cells play a central role in initiating and orchestrating CNS inflammation. In this scenario, $\mathrm{CD}^{+} \mathrm{T}$ cells, activated in the periphery, infiltrate the CNS, where, by secreting cytokines and chemokines, they start an inflammatory cascade. It was postulated that Th1 cells, which produce IFN- $\gamma$, mediate inflammation of the CNS in MS, while Th2 cells, which produce IL-4, have a beneficial effect in disease, because of their antagonistic effect on Th1 cells. The Th1/Th2 paradigm remained the prevailing view of MS pathogenesis until 2005, when a new lineage, Th17, was discovered. In a relatively short period of time it became apparent that Th17 cells play a crucial role in many inflammatory diseases, including MS. Numerous findings support the view that Th17 cells play an essential role in autoimmune CNS inflammation, perhaps mainly in the initial phases of disease. Th1 cells likely contribute to pathogenesis, with their role possibly more pronounced later in disease. Hence, the current view on the role of Th cells in MS pathogenesis can be called the Th17/Th1 paradigm [15].

There are evidences that adaptive immune system can be affected by very low magnetic field. Magnetic field as low as geomagnetic field can significantly change lymphocyte $\mathrm{Ca}^{2+}$ uptake [16]. In addition, through three proposed mechanisms, geomagnetic field can change leukocyte behavior, activation and adhesion by inducing the membrane-mediated signal transduction cascades, like the time that a ligand-receptor interaction activates the cell $[17,18,19]$. Those mechanisms include changes of ion flux, especially $\mathrm{Ca}^{2+}$ across cell membrane, cyclotron resonance and dissociation of protein-ion complex by changing quantum states of ions in their structures in the membrane proteins [17]. There are also evidences that magnetic fields can enhance release of reactive 
oxygen species by $\mathrm{T}$ cells and macrophages [18].

S Wing et al., [20] found that ALindex (a proxy for the westward auroral electrojet and a measure of geomagnetic activity) and the incidences of autoimmune diseases giant cell arteritis and rheumatoid arthritis all have a major periodicity of about 10 years and a secondary periodicity at 4-5 years. Geomagnetic activity may explain the temporal and spatial variations in both diseases incidence, although the mechanism is unknown. Authors concluded that the link with solar, geospace and atmospheric parameters need to be investigated as well as these novel findings warrant examination in other populations and with other autoimmune diseases.

Therefore, on the example of autoimmune diseases the effect of geomagnetism on human immunity has so far been studied through long-term observations. Recently, in a similar contingent, we found an immediate immunotropic effects of the Earth's magnetic field by analyzing the relationships between immunity parameters and the geomagnetic Ap-index [21]. The object of observation were 74 patients with MS and 14 patients with radiculopathies, who in the period from September 2014 to November 2018 carried out a one-time assessment of immune status by the relative content in the blood of lymphocytes of $\mathrm{CD}^{+}, \mathrm{CD}^{+}, \mathrm{CD}_{25} 5^{+}, \mathrm{CD}^{+}, \mathrm{CD} 56^{+}$and $\mathrm{CD} 22^{+}$phenotypes and serum level of Immunoglobulins $\mathrm{M}, \mathrm{G}, \mathrm{A}$ as well as CIC and IL-1 $\beta$. On the day of blood capture and during the previous 7 days, retrospectively recorded the geomagnetic Ap-index, using a publicly available information resource http://wdc.kugi.kyoto-u.ac.jp/kp/index.html. During the week, the average level of Apindex ranged from $12 \div 20 \mathrm{nT}$. The correlation coefficients between the Apindex on the day of blood collection and 1, 3 and 7 days before it and the level of
$\mathrm{CD}^{+} \mathrm{CD}^{+}$lymphocytes were $-0,57$; -0,48; 0,55 i $-0,52$ respectively, while on other days were in the range of $-0,35 \div 0,05$. In contrast, with the level of $\mathrm{CD}^{+} 6^{+}$ lymphocytes Ap-index correlates positively and almost mirror $(0,56 ; 0,43 ; 0,54,0,57$ and $0,34 \div-0,08$ respectively), due to the reciprocity of their levels $(r=-0,80)$. Also positively, but much weaker, correlates the Ap-index with the level of $\mathrm{CD}^{+}{ }^{+} \mathrm{CD} 4{ }^{+} \mathrm{CD} 25^{+}$lymphocytes $(0,35 ; 0,25$; $0,45,0,31$ and $0,22 \div-0,14$ respectively). In contrast, with the level of IL-1 $\beta$ Ap-index correlates significantly only on the day of blood collection and 2 days before $(r=0,21$ and 0,31 respectively), and with other registered parameters of immunity the correlation is insignificant. The canonical correlation between Ap-indices for 7 days before and on the day of blood collection, on the one hand, and the levels of $\mathrm{CD}^{+}$, $\mathrm{CD}^{+} 6^{+}, \mathrm{CD} 25^{+}$and $\mathrm{CD} 8^{+}$lymphocytes and the concentration of IgM and IL-1 $\beta$ - on the other hand, was very strong: $\mathrm{R}=0,741$; $\mathrm{R}^{2}=0,549 ; \quad \chi_{(42)}^{2}=130 ; \quad \mathrm{p}<10^{-6}$. Thus, disturbances of the geomagnetic field (Apindex) has a significant immediate modulating effect on the level of immune parameters in the blood, mostly T-helpers (suppressing) and natural killers (enhancing).

The aim of this study, conducted on a similar design, was to identify the immunotropic effects of disturbances of the geomagnetic field on another contingent of people.

\section{Methods}

Participants. The object of observation were 21 men (24-63 y) and 20 women (33-62 y) former sportsmen with neuroendocrine-immune complex dysfunction (increased level of HRVsmarkers of sympathetic tone and decreased - vagal tone, moderate hypocortisolemia, decreased parameters of phagocytosis by 
neutrophils of gram-negative and grampositive bacteria, the level of T-helpers, but increased levels of NK- and B-lymphocytes, Igg $\mathrm{G}$ and $\mathrm{M}$ ). Each patient was examined twice with an interval of 4 days. Procedure / Test protocol /Skill test trial / Measure / Instruments. Observations were carried out on 09.06. and 13.06. 2015 (13 men and 3 women), 14.09. and 18.09. 2015 (1 man and 4 women), 27-28.03. and 04-05.04. 2018 (3 men and 7 women), 28.01 and 01.02. 2019 (4 men and 6 women). Retrospectively we recorded the geomagnetic Ap-Index (average value of variations of the Earth's magnetic field as a marker of geomagnetic activity) on the day of testing and during the previous 7 days, using a publicly available information resource https://www.spaceweatherlive.com [22].

Immune status evaluated on a set of I and II levels recommended by the WHO as described in the manuals [23]. For phenotyping subpopulations of lymphocytes used the methods of rosette formation with sheep erythrocytes on which adsorbed monoclonal antibodies against receptors CD3, CD4, CD25, CD8, CD22 and CD56 from company "Granum" (Kharkiv) with visualization under light microscope with immersion system. Subpopulation of T cells with receptors high affinity (T-active) determined by test of "active" rosette formation. The state of humoral immunity judged by the concentration in serum of Circulating Immune Complexes (by polyethylene glycol precipitation method) and Immunoglobulins classes $\mathrm{M}, \mathrm{G}, \mathrm{A}$ (ELISA, analyzer "Immunochem", USA). In addition, the level of $\mathrm{C}$-reactive Protein and IL-1 $\beta$ was determined (by the ELISA with the use of analyzer "RT-2100C" and corresponding set of reagents from "VectorBest", RF).

Data collection and analysis.Parameters of phagocytic function of neutrophils estimated as described by SD Douglas and PG Quie [24] with moderately modification by MM Kovbasnyuk [25,26]. The objects of phagocytosis served daily cultures of Staphylococcus aureus (ATCC N 25423 F49) as typical specimen for Grampositive Bacteria and Escherichia coli (O55 K59) as typical representative of Gramnegative Bacteria. Both cultures obtained from Laboratory of Hydro-Geological Regime-Operational Station JSC "Truskavets'kurort". Take into account the following parameters of Phagocytosis: activity (percentage of neutrophils, in which found microbes - Hamburger's Phagocytic Index PhI), intensity (number of microbes absorbed one phagocytes - Microbial Count MC or Right's Index) and completeness (percentage of dead microbes - Killing Index KI). On the basis of the recorded partial parameters of Phagocytosis, taking into account the Neutrophils $(\mathrm{N})$ content of 1 L blood, we calculated the integral parameter - Bactericidal Capacity of Neutrophils (BCCN) by the formula [25]:

$\operatorname{BCCN}\left(10^{9}\right.$ Bacteria $\left./ \mathrm{L}\right)=\mathrm{N}$ $\left(10^{9} / \mathrm{L}\right) \cdot \mathrm{PhI}(\%) \bullet \mathrm{MC}(\mathrm{Bact} / \mathrm{Phag}) \cdot \mathrm{KI}$ $(\%) \cdot 10^{-4}$

In portion of the capillary blood we counted up Leukocytogram (LCG) (Eosinophils, Rod-shaped and Polymorphonucleary Neutrophils, Lymphocytes and Monocytes).

We calculated also the Entropy (h) of Immunocytogram (ICG) and Leukocytogram (LCG) using IL Popovych's formulas [27]:

$$
\mathrm{hICG}=-\left[\mathrm{CD} 4 \bullet \log _{2} \mathrm{CD} 4+\mathrm{CD} 8 \bullet \log _{2}\right.
$$

$\mathrm{CD} 8+\mathrm{CD} 22 \cdot \log _{2} \mathrm{CD} 22+\mathrm{CD} 56 \cdot \log _{2}$ $\mathrm{CD} 56] / \log _{2} 4$

$\mathrm{hLCG}=-\left[\mathrm{L} \cdot \log _{2} \mathrm{~L}+\mathrm{M} \cdot \log _{2} \mathrm{M}+\right.$ $\mathrm{E} \bullet \log _{2} \mathrm{E}+\mathrm{PMNN} \bullet \log _{2} \mathrm{PMNN}+\mathrm{RSN} \bullet \log _{2}$ $\mathrm{RSN}] / \log _{2} 5$

Statistical analysis. Results processed by using the software package "Statistica 64". 


\section{Results}

During the week before testing, the average level of Ap-index was in the range of $7 \div 13$ nT (Fig. 1).

Screenings of correlations between Apindices and immune parameters performed (Table 1).

Maximum coefficients of multiple correlation with immunity parameters were detected for Ap-index on the eve of blood sampling $(\mathrm{R}=0,768)$ and 5 days before it $(\mathrm{R}=0,758)$ while the minimum on 3 $(\mathrm{R}=0,541)$ and $2(\mathrm{R}=0,479)$ days before sampling.

It is noteworthy that the patterns of the average level of Ap-indices and coefficients of multiple Ap/Immune correlation $R$, determination $\mathrm{R}^{2}$ and Adjusted $\mathrm{R}^{2}$ are almost the same. That is, the higher the Ap-index, the stronger it affects the parameters of immunity. However, the nature of the impact is ambiguous.

In particular, on the eve of blood sampling, i.e. at the peak of Ap/Immune correlations, there is a maximum suppressive (downregulating) effect of the disturbances of the geomagnetic field on phagocytosis, as well as T-killer and Blymphocytes, CIC and Igg M\&A levels while upregulating effect on NKlymphocytes. Instead, on the day of blood sampling, the connections with phagocytose, T-killer and NK-lymphocytes, CIC and $\operatorname{IgM}$ significantly weaken or disappear, with B-lymphocytes do not change, however, with IgA are strengthened, and with T-helper lymphocytes become significant. On the other hand, 2 days before testing, there was no significant correlation of these parameters with Ap-index, however, there were positive connections with pan- lymphocytes and negative - with monocytes and C-reactive protein level.

It seems that the disturbances of the geomagnetic field downregulates with $1 \div 0,5$ day delay the activity, intensity and, especially, the completion of phagocytosis by neutrophils of gram-positive and gramnegative microbes, and the level in the blood of B-lymphocytes and their secretion of Igg $\mathrm{M}$ and $\mathrm{A}$ (but not $\mathrm{IgG}$ ) with the formation of CIC as well as the level of Thelper and T-killer lymphocytes, instead upregulates the level of NK-lymphocytes. The downregulation the level of monocytes and C-RP (but not IL-1 $\beta$ ), as well as the upregulation the level of pan-lymphocytes is realized with a delay of $2 \div 1,5$ days.

The second peak of Ap/Immune correlations was detected 5 days before testing. But, despite the almost identical values of $R, R^{2}$ and Adjusted $R^{2}$ with the first peak, their structure differs significantly. In particular, negative connections of Ap-5 (as well as Ap-6 and Ap-7) with phagocytosis parameters as well as $\mathrm{CIC}$ and IgM (but not IgA and $\mathrm{Th}$ ) are reversed to positive or leveled. In addition, there are significant links with levels of eosinophils as well as "active" and $\mathrm{CD} 3{ }^{+} \mathrm{CD} 4^{+} \mathrm{CD} 25^{+}$lymphocytes.

Finally, the relationship between Apindices for $7 \div 0$ days, on the one hand, and the registered immunity parameters, on the other hand, was analyzed. The analysis revealed two significant pairs of canonical roots.

The geomagnetic root of the first pair (Table 2) is expected to receive the maximum positive load from the Ap-index on the eve of blood sampling and the second in rank - from the Ap-index on the day of testing. In contrast, Ap-7, Ap-4 and Ap-3 indices give negative factor loads.

The immune root of the first pair is represented mainly by the parameters that are subject to downregulation by variations of the magnetic field with a delay of $1 \div 0,5$ 
day while to upregulation with a delay of 7 , 4 and 3 days. A positive correlation of Ap-1 and Ap0 with the level of 0-lymphocytes also reflects their immunosuppressive effect.

Taken together, the variations of the magnetic field in these periods before blood collection determine this constellation of immune parameters by $85 \%$ (Fig. 3).

The geomagnetic root of the second pair was without the top component of the first pair (Ap-1), and all seven components give a load with the same sign (Table 3 ).

The immune root of the second pair is represented by rod-shaped neutrophils and eosinophils which are subject to the upregulation by Ap-4, by monocytes and C-reactive protein downregulated by Ap-2 and Lymphocytes in total upregulated by Ap-2. But the main array is represented by immune parameters that are subject to suppression or activation by the variations of the magnetic field on other days.

Taken together, the variations of the magnetic field determine this constellation of immune parameters by $74 \%$ (Fig. 3 ).

\section{Discussion}

On the PubMed and PMC resources we found only works on the long-term immunotropic effects of the artificial magnetic field [28,29,30], which makes it impossible to compare their data with ours.

Therefore, we are pleased to consider YuP Gorgo's et al., (2018) [31] recent study. The monitoring of specific intensity of bacteria Photobacterium phosphoreum luminescence has been carried out for 2 months (September-October 2015) and it was compared to the daily values of activity of the geomagnetic field in the conditions of Kyïv, during the research of bioluminescence. Variation determination of the geomagnetic field was conducted from data of Space Environment Center, NOAA\&U.S. Air Force. The inverse proportional reliable average correlation was defined between the values of specific bacterial luminescence and the K-p ( $\mathrm{r}=$ $0,41)$ as well as $A-p(r=-0,41)$ indexes of the geomagnetic field, and with the values of flux of Sun radiation at a wavelength 10,7 $\mathrm{cm}$ - reliable directly proportional correlation $(\mathrm{r}=0,305)$. Interestingly, the average values of Ap-indexes were close to those in our observations (in September $13,7 \pm 2,68 \mathrm{nT}$; in October $14,9 \pm 1,90 \mathrm{nT}$ ). Surprising is the proximity of the force of influence of the intensity of variations of the magnetic field on the day of testing (Ap0) both on the manifestation of bacterial activity and phagocytic function of neutrophils (Table 1). This, in our opinion, confirms the direct effect of the geomagnetic field on human neutrophils. The decrease in the level of T-helpers $(r=-$ $0,27)$ and B-lymphocytes $(r=-0,19)$ reflects, in our opinion, the weakening of their expression of CD4 and CD22 receptors, respectively, as evidenced by the positive correlation of the Ap-index with the level of 0 -lymphocytes $(\mathrm{r}=0,26)$.

It was proposed that membranemediated $\mathrm{Ca}^{2+}$ signaling processes are involved in the mediation of the electromagnetic field effects on the immune system [32]. Application of low frequency electromagnetic fields produce parallel shifts in $\mathrm{Ca}^{2+}$ uptake and DNA replication intensity in stimulated lymphocytes [33]. Exposure of immune cells to static magnetic field resulted in decrease of phagocytic activity, inhibition of mitogenic response to Con A in lymphocytes and enhancement of apoptosis in thymic cells [34]. Together, the data demonstrate the possibility of $\mathrm{Ca}^{2+}$ signaling-mediated immunomodulating effects of exposure to magnetic fields.

Back in 1990, YuP Limansky (1990) [35] hypothesized acupuncture points as polymodal receptors of the ecoceptive 
sensitivity system._In the process of hypothesis development in 2003 an existence of separate functional system of regulation of electromagnetic balance of organism has been substantiated and a working conception of light therapy has been formulated [36]. As a basis, there is a possibility to use the acupuncture points for input of biologically necessary electromagnetic waves into the system of their conductors in a body that might be considered as a transport facility for energy of the polarized electromagnetic waves. Zones-recipients are organ shaving an electromagnetic dysbalance due to excess of biologically inadequate radiation and being the targets for peroxide oxidation. Foremost, a body has the neuro-hormonal and immune regulatory systems. Electromagnetic stimulation or modification of functions of the zones-recipients determines the achievement of therapeutic and useful effects, and their combination with local reparative processes allows to attain a clinical goal. Authors show the experimental facts in support of a hypothesis that a living organism can perceive an action of the electromagnetic fields of optical range not only via the visual system, but also through the off-nerve receptors (specific energy-sensitive proteins detecting critical changes of energy in cells and functioning as the "sensory" cell systems), as well as via the acupuncture points.

The effect of physical activity can be considered as a prototype of stress with all the shifts in hormonal and immune systems that are inherent in the body's response to stress. The IgG level increased in mice that received IL-2 while exercising [37].

Results of the conducted researches testify that the reconstruction of the healthimproving, educationaleducational process in the sphere of physical culture with the help of its structural restructuring, differentiation and program-content maintenance, contributes to satisfaction of cognitive, motor and psycho-emotional needs of the personality and development of a set of abilities in the field of ability motor experience, developing individual health and leading a healthy lifestyle [38].

Differentially directed entropy changes under the influence of natural adaptogens are, as a rule, normalizing in nature and predetermined by both its initial levels and other predictors [39].

V Zaporozhan and A Ponomarenko (2010) [40] propose that proteins of the Cryptochrome family (CRY) are "epigenetic sensors" of the magnetic field fluctuations, i.e., magnetic field-sensitive part of the epigenetic controlling mechanism. It was shown that CRY represses activity of the major circadian transcriptional complex CLOCK/BMAL1. At the same time, function of CRY, is apparently highly responsive to weak magnetic field because of radical pairs that periodically arise in the functionally active site of CRY and mediate the radical pair mechanism of magnetoreception.

\section{Conclusion}

It is known that the circadian complex influences function of every organ and tissue, including modulation of both NF- $\kappa$ B- and glucocorticoids-dependent signaling pathways. Thus, magnetic fields and solar cycles-dependent geomagnetic field fluctuations are capable of altering expression of genes related to function of $\mathrm{NF}-\kappa \mathrm{B}$, hormones and other biological regulators.

In addition, the effect of geomagnetism on immunocytes through the nervous and endocrine systems seems quite real. Evidence of this was obtained by us on the same contingent and will be reflected in the next article, already prepared for publication. 


\section{Acknowledgment}

We express our sincere gratitude to administration of clinical sanatorium "Moldova" (Truskavets') for help in carrying out immune tests as well as Danylo Mel'nyk for Ap-index monitoring.

\section{Compliance with Ethical Standards}

Tests in patients are conducted in accordance with positions of Helsinki Declaration 1975, revised and complemented in 2002, and directive of National Committee on ethics of scientific researches. During realization of tests from all participants the informed consent is got and used all measures for providing of anonymity of participants.

Informed Consent Informed consent was obtained from all individual participants included in the study. All subjects of the institutional survey gave consent for anonymized data to be used for publication purposes.

Conflict of Interest The authors declare that they have no conflict of interest.

\section{References}

1. Chizhevsky, AL. (1976). The Terrestrial Echo of Solar Storms. Moscow. Mysl; 366. [in Russian].

2. Chizhevsky, AL. (1995).The Cosmic Pulse of Life. The Earth is Embraced by the Sun. Heliotaraxia. Moscow. Mysl; 766. [in Russian].

3. Halberg, F, Cornélissen, G, Otsuka, K, Watanabe, Y, Katinas, GS, Burioka, N, Delyukov, A, Gorgo, Y et al. (2000). Crossspectrally coherent $\sim 10.5$ - and 21-year biological and physical cycles, magnetic storms and myocardial infarctions. Neuro Endocrinology Letters. 21(3), 233-258. PMID: 11455355

4. Zhadin, MN. (2001). Review of Russian literature on biological action of DC and low-frequency AC magnetic fields.
Bioelectromagnetics, 22(1), 27-45. doi:10.1002/1521-186x(200101)22:1

$<27$ :aid-bem4> 3.0.co;2-2

5. Dubrov, A. (2013). The Geomagnetic Field and Life: Geomagnetobiology. Springer.

6. Hanslmeier, A. (2007). The Sun and Space Weather. 2. Dordrecht: Springer.

7. Abdollahi, F, Sajedi, SA. (2014). Correlation of multiple sclerosis (MS) incidence trends with solar and geomagnetic indices: Time to revise the method of reporting MS epidemiological data. Iran $\mathrm{J}$ Neurol. 13(2), 64-69.

8. Sajedi, SA, Abdollahi, F. (2017). Which Environmental Factor Is Correlated with Long-Term Multiple Sclerosis Incidence Trends: Ultraviolet B Radiation or Geomagnetic Disturbances? Mult Scler Int. 4960386. doi:10.1155/2017/4960386.

9. Kirschvink, JL, Kobayashi-Kirschvink, A, Diaz-Ricci, JC, Kirschvink, SJ. (1992a). Magnetite in human tissues: a mechanism for the biological effects of weak ELF magnetic fields. Bioelectromagnetics. Suppl 1, 101-113.

10. Kirschvink, JL, Kobayashi-Kirschvink, A, Woodford, BJ. (1992b). Magnetite biomineralization in the human brain. Proc Natl Acad Sci USA. 89(16), 7683-7687. doi: 10.1073 /pnas.89. 16. 7683.

11. Breus, TK, Ozheredov, VA, Syutkina, EV, Rogoza, AN. (2008). Some aspects of the biological effects of space weather. J Atmos Sol-Terr Phy. 70(2-4), 436-441.

12. Levine, SM, Chakrabarty, A. (2004). The role of iron in the pathogenesis of experimental allergic encephalomyelitis and multiple sclerosis. Ann NYAS. 1012, 252266. doi: 10.1196 /annals. 1306.021 .

13. Lebel, RM, Eissa, A, Seres, P, Blevins, G, Wilman, AH. (2012). Quantitative highfield imaging of sub-cortical gray matter in 
multiple sclerosis. Mult Scler. 18(4), 433441. doi: 10.1177 / 1352458511428464 .

14. Christiansen, CF, Christensen, S, Farkas, DK, Miret, M, Sorensen, HT, Pedersen, L. (2010). Risk of arterial cardiovascular diseases in patients with multiple sclerosis: a population-based cohort study. Neuroepidemiology, 35(4), 267-274. doi: 10.1159/000320245.

15. Rostami, A, Ciric, B. (2013). Role of Th17 cells in the pathogenesis of CNS inflammatory demyelination. J Neurol Sci. 333(1-2), 76-87. doi:10.1016/j.jns.2013.03.002

16. Walleczek, J. (1992). Electromagnetic field effects on cells of the immune system: the role of calcium signaling. FASEB J. 6(13), 3177-3185.

17. Jandova, A, Mhamdi, L, Nedbalova, M, Cocek, A, Trojan, S, Dohnalova, A, Pokorny, J. (2005). Effects of Magnetic Field 0.1 and $0.05 \mathrm{mT}$ on Leukocyte Adherence Inhibition. Electromagn Biol Med. 24(3), 283-292. doi: $10.1080 / 15368370500379681$.

18. Simko, M, Mattsson, MO. (2004). Extremely low frequency electromagnetic fields as effectors of cellular responses in vitro: possible immune cell activation. J Cell Biochem. 93(1), 83-92. doi: 10.1002/jcb.20198.

19. Cocek, A, Hahn, A, Ambrus, M, Dohnalova, A, Jandova, A, Pokorny, J. (2008). Changes of leukocyte adherence ability under the influence of magnetic field in the course of a treatment of patients with laryngeal and pharyngeal carcinoma. Electromagn Biol Med. 27(3), 277-288. doi: $10.1080 / 15368370802277724$.

20. Wing, S, Rider, LG, Johnson, JR, et al. (2015). Do solar cycles influence giant cell arteritis and rheumatoid arthritis incidence? BMJ Open. 5(5): e006636. doi:10.1136/bmjopen-2014-006636.
21. Popovych, IL, Gozhenko, AI, Badiuk, NS, Napierata, M, Muszkieta, R, Zukow, W, Yanchij, RI, Lapovets', NYe, Lapovets', LYe, Tserkovnyuk, RG, Akimova, VM, Nahurna, YV, Martianova, OI, Vivchar, RYa, Chendey, IV, Ruzhylo, SV. (2021). Relationships between geomagnetic Apindex and parameters of the immunity in patients with multiple sclerosis and radiculopathies. Journal of Education, Health and Sport, 11(3), 77-90.

22. https://www.spaceweatherlive.com (01.02.2019).

23. Lapovets', LYe, Lutsyk, BD. (2004). Laboratory Immunology [in Ukrainian]. Kyiv; 173.

24. Douglas, SD, Quie, PG. (1981). Investigation of Phagocytes in Disease. Churchil; 110.

25. Kul'chyns'kyi, AB, Kovbasnyuk, MM, Kyjenko, VM., Zukow, W, Popovych, IL. (2016). Neuro-immune relationships at patients with chronic pyelonephrite and cholecystite. Communication 2. Correlations between parameters EEG, HRV and Phagocytosis. Journal of Education, Health and Sport. 6(10), 377-401.

26. Popovych, IL, Kul'chyns'kyi, AB, Gozhenko, AI, Zukow, W, Kovbasnyuk, MM, Korolyshyn, TA. (2018). Interrelations between changes in parameters of HRV, EEG and phagocytosis at patients with chronic pyelonephritis and cholecystitis. Journal of Education, Health and Sport, 8(2), 135-156.

27. Popovych, IL. (2007). Information effects of bioactive water Naftyssya in rats: modulation entropic, prevention desynchronizing and limitation of disharmonizing actions water immersion stress for information components of neuroendocrine-immune system and metabolism, which correlates with gastroprotective 
effect. Medical Hydrology and Rehabilitation, 5(3), 50-70. [in Ukrainian].

28. Bonhomme-Faivre, L, Marion, S, Forestier, F, Santini, R, Auclair, H. (2003). Effects of electromagnetic fields on the immune systems of occupationally exposed humans and mice. Arch Environ Health. 58(11), 712-717. doi:10.3200/AEOH.58.11.712-717.

29. Frahm, J, Lantow, M, Lupke, M, Weiss, DG, Simkó, M. (2006). Alteration in cellular functions in mouse macrophages after exposure to $50 \mathrm{~Hz}$ magnetic fields. J Cell Biochem. 99(1), 168-177. doi:10.1002/jcb.20920.

30. Lupke, M, Frahm, J, Lantow, M, et al., (2006).Gene expression analysis of ELF-MF exposed human monocytes indicating the involvement of the alternative activation pathway. Biochim Biophys Acta. 1763(4), 402-412. doi: 10.1016/j.bbamcr. 2006.03.003.

31. Gorgo, YuP, Greckiy, IO, Demydova, OI. (2018). The use of luminos bacteria Photobacterium phosphoreum as a bioindicator of geomagnetic activity. Innov Biosyst Bioeng. 2(4), 271-277. doi:10.20535/ibb.2018.2.4.151459

32. Walleczek J. (1992). Electromagnetic field effects on cells of the immune system: the role of calcium signaling. FASEB J. 6(13):3177-85.

doi:

10.1096/fasebj.6.13.1397839. PMID: 1397839.

33. Conti, P, Gigante, GE, Alesse, E, Cifone, MG, Fieschi, C, Reale, M, Angeletti, PU. (1985). A role for Ca2+ in the effect of very low frequency electromagnetic field on the blastogenesis of human lymphocytes. FEBS Lett. 181, 2832.

34. Flipo, D, Fournier, M, Benquet, C, Roux, P, Le Boulaire, C, Pinsky, C, LaBella, FS, Krzystyniak, K. (1998).
Increased apoptosis, changes in intracellular $\mathrm{Ca} 2+$, and functional alterations in lymphocytes and macrophages after 
35. in vitro exposure to static magnetic field. $\mathrm{J}$ Toxicol Environ Health A. 54, 63-76.

36. Limansky, YuP. (1990). Hypothesis about acupuncture points as polymodal receptors of the ecoceptive sensitivity system. Fiziol Zhurn. 36(4), 115-121. [in Russian].

37. Gulyar, SA, Limansky YuP. (2003). Functional system of regulation of electromagnetic balance of organism: mechanisms of primary reception of electromagnetic waves of optical range. Fiziol Zhurn. 49(2), 35-44. [in Ukrainian].

38. Shvets, V., Shkuropat, A. Prosiannikova, Y. \& Golovchenko, I. (2020). Effect of Interleukin-2 on the humoral link of immunity during physical activity. Journal of Physical Education and Sport, 20(S6), 3153-3159.

39. Futornyi, S., Maslova, O., Shmatova, O., Osadcha, O., Rychok, T., Hopey, M. \& Tarnavskiy, A. (2020). Modern aspects of the ecological culture implementation in the physical education process of different population groups. Journal of Physical Education and Sport. 20(S1), 348-353.

40. Popadynets, O. Gozhenko, A. Badyuk, N. Popovych, I. Skaliy, A., Hagner-Derengowska,
M., Napierała, M., Muszkieta, R., Sokołowski, D., Zukow, W., Rybalko, L. (2020). Interpersonal differences caused by adaptogen changes in enropies of EEG, HRV, immunocytogram, and leukocytogram. Journal of Physical Education and Sport, 20(S2), 982-999.

41. Zaporozhan, V, Ponomarenko, A. (2010). Mechanisms of geomagnetic field influence on gene expression using influenza as a model system: basics of physical epidemiology. Int $\mathbf{J}$ Environ Res Public Health. 7(3), 938-965. doi:10.3390/ijerph7030938. 


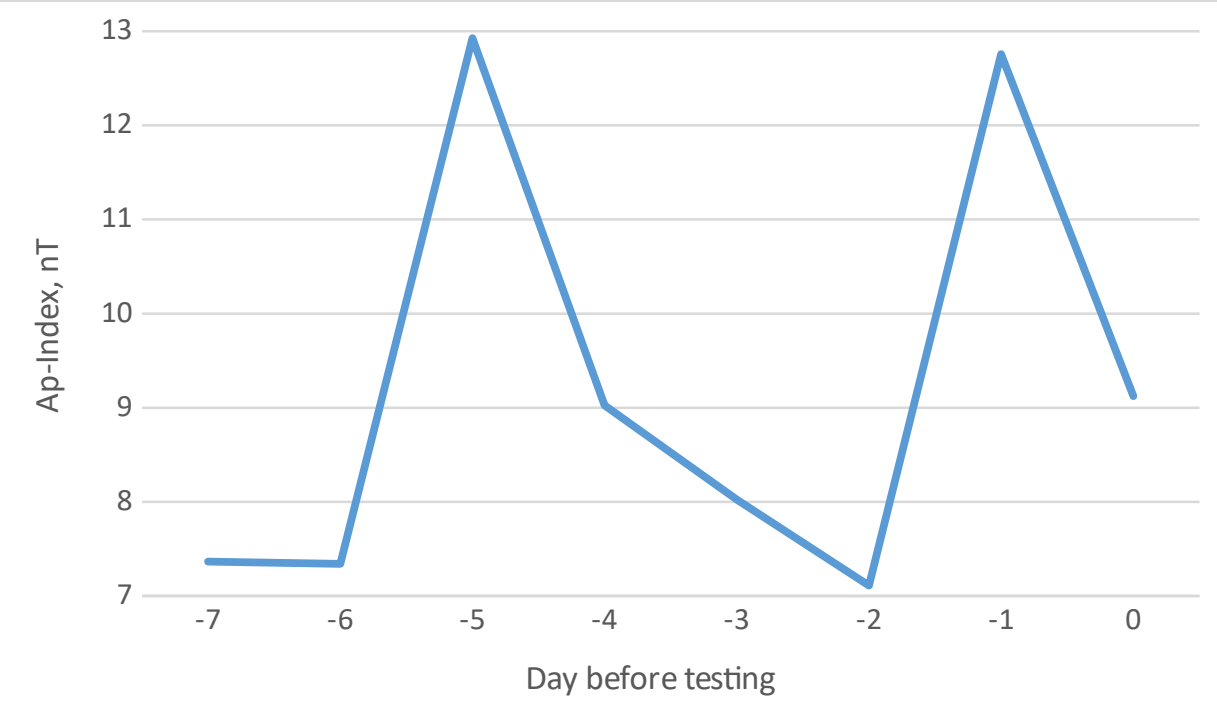

Fig. 1. Values of Ap-Index ( $M \pm S E)$ on the day of testing and during the previous 7 days

Screenings of correlations between Ap-indices and immune parameters performed (Table 1).

Table 1. Matrix of correlations between Ap-Indices and immunity parameters

\begin{tabular}{|l|r|r|r|r|r|r|r|r|}
\hline \multirow{2}{*}{ Variable } & \multicolumn{9}{|l|}{ Correlations } \\
\cline { 2 - 10 } & \multicolumn{9}{|l|}{ Ap-7 } & Ap-6 & Ap-5 & Ap-4 & Ap-3 & Ap-2 & Ap-1 & Ap0 \\
\hline CD25 & 0,10 & 0,24 & 0,27 & 0,06 & 0,09 & $-0,00$ & $-0,08$ & 0,15 \\
\hline CRP & 0,02 & 0,04 & $-0,16$ & $-0,13$ & $-0,04$ & $-0,27$ & 0,06 & 0,03 \\
\hline IL-1 & $-0,07$ & $-0,16$ & $-0,12$ & $-0,08$ & $-0,09$ & $-0,03$ & 0,14 & $-0,03$ \\
\hline CD4 & $-0,14$ & $-0,26$ & $-0,19$ & 0,03 & $-0,05$ & 0,01 & $-0,15$ & $-0,27$ \\
\hline CD3act & $-0,04$ & $-0,23$ & $-0,22$ & $-0,10$ & $-0,19$ & $-0,09$ & 0,04 & $-0,06$ \\
\hline CD22 & $-0,08$ & $-0,17$ & $-0,02$ & 0,03 & $-0,06$ & $-0,11$ & $-0,20$ & $-0,19$ \\
\hline CD56 & 0,07 & 0,07 & $-0,01$ & $-0,09$ & $-0,02$ & $-0,01$ & 0,23 & 0,17 \\
\hline ClC & 0,12 & 0,21 & 0,05 & $-0,06$ & 0,06 & 0,09 & 0,26 & 0,26 \\
\hline IgA & $-0,02$ & 0,02 & 0,19 & 0,13 & 0,07 & $-0,01$ & $-0,21$ & $-0,08$ \\
\hline IgM & $-0,19$ & $-0,30$ & $-0,26$ & $-0,01$ & $-0,11$ & $-0,20$ & $-0,28$ & $-0,40$ \\
\hline PhI St & 0,12 & 0,24 & $-0,14$ & 0,16 & 0,09 & $-0,01$ & $-0,24$ & $-0,09$ \\
\hline MC St & 0,25 & 0,31 & $-0,31$ & $-0,16$ & $-0,06$ & $-0,05$ & 0,25 & 0,30 \\
\hline KI St & 0,48 & 0,41 & 0,09 & 0,25 & 0,31 & 0,08 & $-0,35$ & $-0,01$ \\
\hline BC St & 0,16 & $-0,08$ & 0,43 & 0,42 & 0,36 & 0,17 & $-0,55$ & $-0,39$ \\
\hline Phl E & 0,24 & 0,21 & 0,28 & 0,33 & 0,35 & 0,02 & $-0,48$ & $-0,21$ \\
\hline MC E & $-0,04$ & 0,07 & $-0,28$ & $-0,03$ & $-0,10$ & $-0,21$ & $-0,20$ & $-0,12$ \\
\hline KI E & 0,30 & $-0,14$ & $-0,11$ & 0,20 & 0,21 & 0,02 & $-0,44$ & $-0,41$ \\
\hline BC E & 0,37 & 0,21 & 0,49 & 0,43 & 0,42 & 0,14 & $-0,51$ & $-0,18$ \\
\hline Eosin & 0,28 & 0,14 & 0,17 & 0,29 & 0,32 & $-0,05$ & $-0,51$ & $-0,27$ \\
\hline RS Neu & $-0,08$ & 0,17 & 0,24 & 0,17 & 0,09 & 0,06 & $-0,05$ & 0,08 \\
\hline Lymph & 0,02 & 0,08 & 0,20 & 0,18 & 0,14 & 0,12 & 0,00 & 0,02 \\
\hline Mon & 0,08 & $-0,06$ & 0,14 & $-0,00$ & 0,13 & 0,23 & 0,17 & 0,02 \\
\hline
\end{tabular}

Note. According to calculations by the formula: $|\mathrm{r}|=\left\{\exp \left[2 \mathrm{t} /(\mathrm{n}-1,5)^{0,5}\right]-1\right\} /\left\{\exp \left[2 \mathrm{t} /(\mathrm{n}-1,5)^{0,5}\right]+1\right\}$ for a sample of $\mathrm{n}=82$ critical value $|\mathrm{r}|$ at $\mathrm{p}<0,05(\mathrm{t}>2,00)$ is 0,22 , at $\mathrm{p}<0,01(\mathrm{t}>2,66)$ is 0,29 , at $\mathrm{p}<0,001(\mathrm{t}>3,46)$ is 0,37 . 


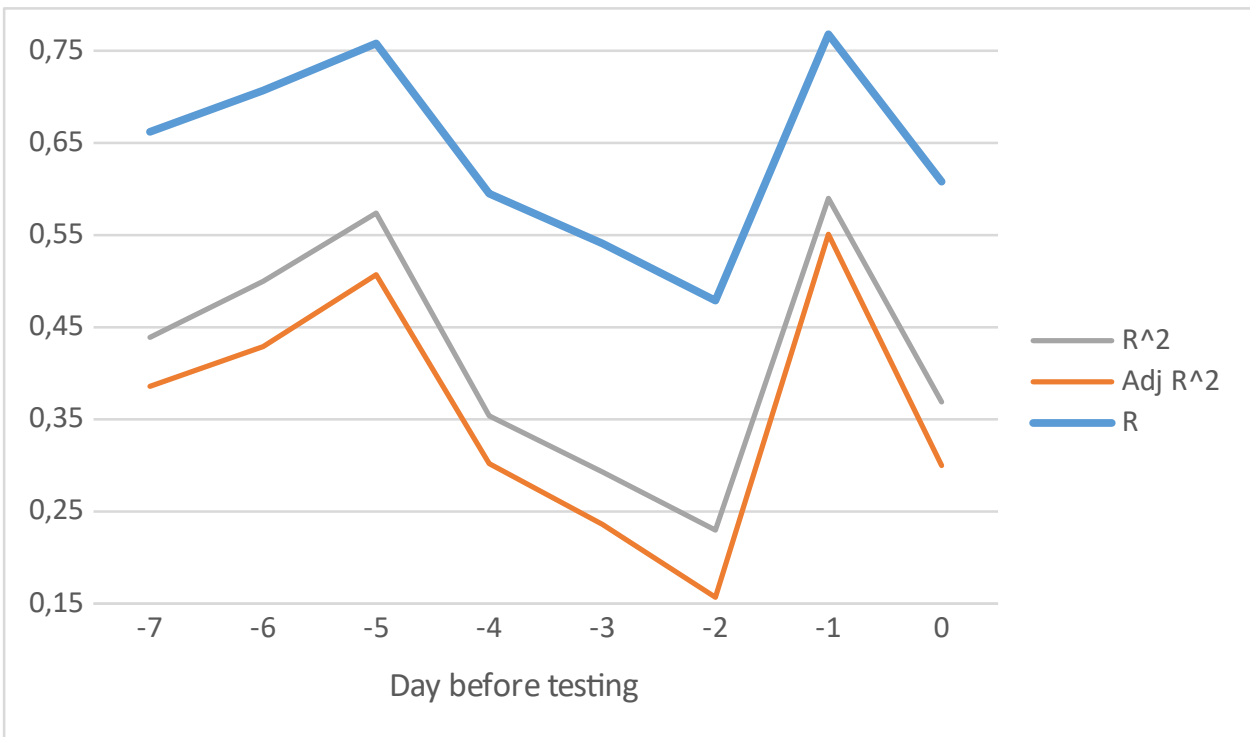

Fig. 2. Dynamics of coefficients of multiple correlation $R$, determination $R^{2}$ and Adjusted $R^{2}$ between Ap-Index and immunity parameters

Table 2. Factor Structure Matrix for first Ap/Immune pair of Canonical Roots

\begin{tabular}{|c|c|}
\hline Left set & Root 1 \\
\hline Ap-1, nT & 0,726 \\
\hline Ap- $0, n T$ & 0,481 \\
\hline Ap-7, nT & $-0,489$ \\
\hline Ap-4, nT & $-0,332$ \\
\hline Ap-3, nT & $-0,290$ \\
\hline Right set & Root 1 \\
\hline Microbial Count for E. coli, Bacteria/Phagocyte & $-0,723$ \\
\hline Bactericidal Capacity vs E. coli, $10^{9} \mathrm{Bac} / \mathrm{L}$ & $-\mathbf{0 , 5 5 7}$ \\
\hline Immunoglobulins A, g/L & $-0,459$ \\
\hline Killing Index vs Staph. aureus, \% & $-0,444$ \\
\hline Microbial Count for Staph. aureus, Bacter/Phag & $-0,438$ \\
\hline Bactericidal Capacity vs Staph. aureus, $10^{9} \mathrm{Bac} / \mathrm{L}$ & $-0,433$ \\
\hline Killing Index vs E. coli, \% & $-0,374$ \\
\hline Phagocytosis Index vs E. coli, \% & $-0,344$ \\
\hline Immunoglobulins $\mathrm{M}, \mathrm{g} / \mathrm{L}$ & $-0,342$ \\
\hline $\mathrm{CD}^{+} \mathrm{CD}^{+} \mathrm{T}$-helper Lymphocytes & $-0,302$ \\
\hline Entropy of Immunocytogram & $-0,244$ \\
\hline CD22 ${ }^{+}$B-Lymphocytes, \% & $-0,241$ \\
\hline $\mathrm{CD}^{+}{ }^{+}$T-active Lymphocytes, $\%$ & $-0,121$ \\
\hline Circulating Immune Complex, units & $-0,110$ \\
\hline 0 -Lymphocytes, $\%$ & 0,322 \\
\hline
\end{tabular}




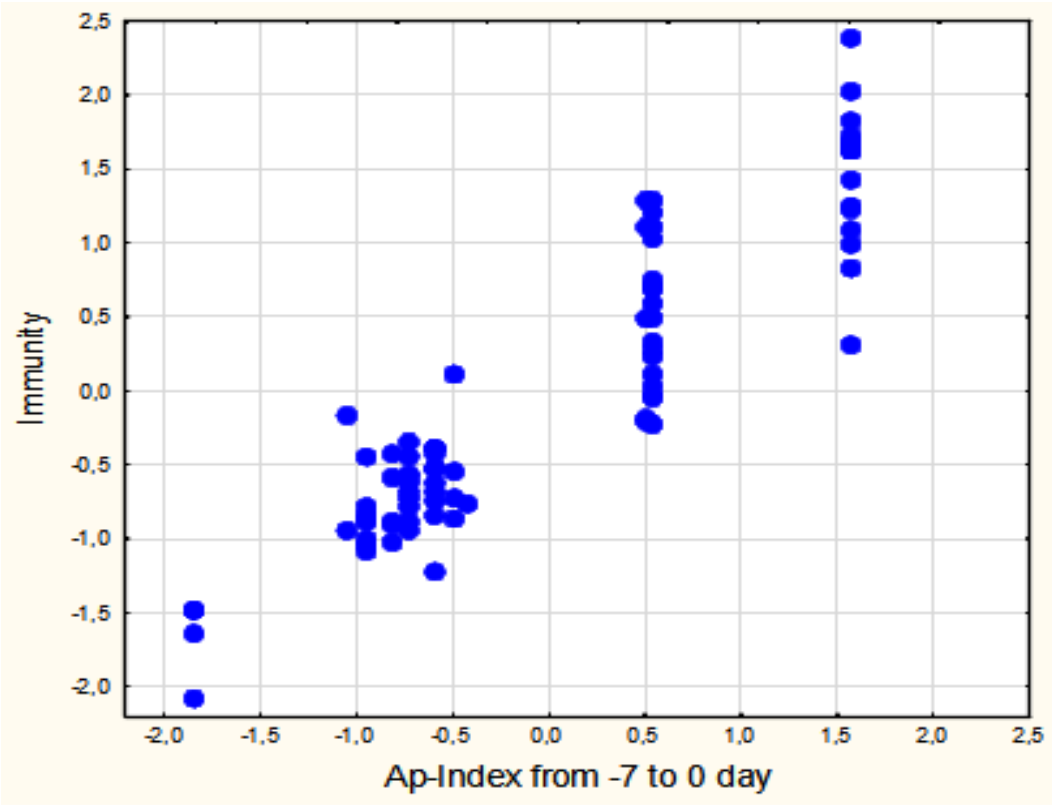

$\mathrm{R}=0,921 ; \mathrm{R}^{2}=0,849 ; \chi^{2}{ }_{(200)}=375 ; \mathrm{p}<10^{-6} ; \Lambda$ Prime $=0,0028$

Fig. 3. Scatterplot of canonical correlation between Ap Geomagnetic indices before 7 days and on day blood sampling (Xline) and Immune parameters (Y-line). First pair of Roots

Table 3. Factor Structure Matrix for second Ap/Immune pair of Canonical Roots

\begin{tabular}{|l|l|}
\hline Left set & Root $\mathbf{~}$ \\
\hline Ap-6, nT & $\mathbf{0 , 7 4 5}$ \\
\hline Ap-7, nT & $\mathbf{0 , 6 5 4}$ \\
\hline Ap-3, nT & $\mathbf{0 , 4 8 3}$ \\
\hline Ap-5, nT & $\mathbf{0 , 4 4 0}$ \\
\hline Ap-0, nT & $\mathbf{0 , 3 2 8}$ \\
\hline Ap-2, nT & $\mathbf{0 , 2 2 7}$ \\
\hline Ap-4, nT & $\mathbf{0 , 3 1 1}$ \\
\hline Right set & Root $\mathbf{2}$ \\
\hline Immunoglobulins A, g/L & $\mathbf{- 0 , 6 0 3}$ \\
\hline CD3 $^{+}$CD4 ${ }^{+}$T-helper Lymphocytes & $\mathbf{- 0 , 4 8 4}$ \\
\hline CD3 $^{+}$T-active Lymphocytes, \% & $\mathbf{- 0 , 2 8 9}$ \\
\hline CD22 ${ }^{+}$B-Lymphocytes, \% & $\mathbf{- 0 , 2 5 5}$ \\
\hline Phagocytosis Index vs E. coli, \% & $\mathbf{- 0 , 2 4 2}$ \\
\hline Entropy of Immunocytogram & $\mathbf{- 0 , 2 0 8}$ \\
\hline Interleukin-1, ng/L & $\mathbf{- 0 , 1 5 6}$ \\
\hline Monocytes, \% & $\mathbf{- 0 , 2 2 6}$ \\
\hline C-Reactive Protein, mg/L & $\mathbf{- 0 , 0 5 8}$ \\
\hline Lymphocytes in total, \% & $\mathbf{0 , 2 1 6}$ \\
\hline Microbial Count for Staph. aureus, Bac/Phagocyte & $\mathbf{0 , 5 2 0}$ \\
\hline Killing Index vs E. coli, \% & $\mathbf{0 , 5 1 5}$ \\
\hline CD3 ${ }^{+}$CD4 ${ }^{+}$CD25 ${ }^{+}$T-Lymphocytes, \% & $\mathbf{0 , 3 8 1}$ \\
\hline 0-Lymphocytes, \% & $\mathbf{0 , 3 5 7}$ \\
\hline Phagocytosis Index vs Staph. aureus, \% & $\mathbf{0 , 2 7 0}$ \\
\hline Bactericidal Capacity vs Staph. aureus, $10^{9}$ Bac/L & $\mathbf{0 , 2 6 2}$ \\
\hline Bactericidal Capacity vs E. coli, $10^{9}$ Bacteria/L & $\mathbf{0 , 1 7 2}$ \\
\hline Rod-shaped Neutrophils, \% & $\mathbf{0 , 1 8 0}$ \\
\hline Eosinophils, \% & $\mathbf{0 , 1 4 8}$ \\
\hline & \\
\hline
\end{tabular}




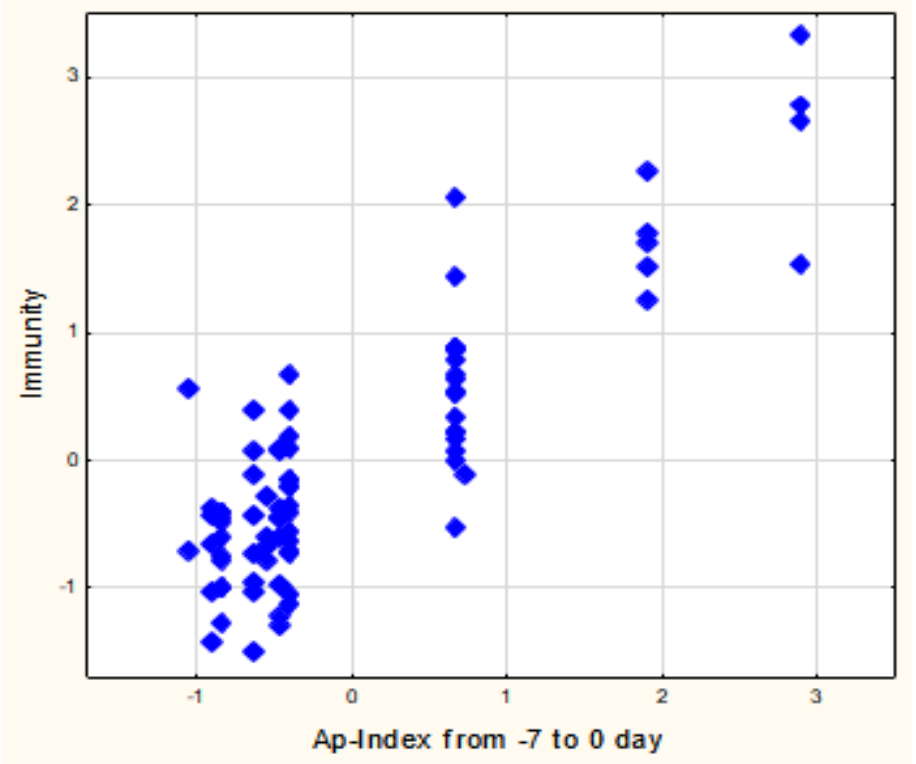

$\mathrm{R}=0,862 ; \mathrm{R}^{2}=0,743 ; \chi_{(168)}^{2}=255 ; \mathrm{p}<10^{-4} ; \Lambda$ Prime $=0,0187$

Fig. 4. Scatterplot of canonical correlation between Ap Geomagnetic indices before 7 days and on day blood sampling (Xline) and Immune parameters (Y-line). Second pair of Roots 